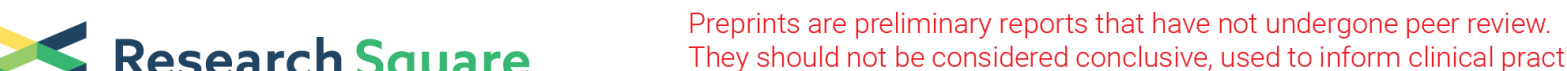 Research Square They should not be considered conclusive, used to inform clinical practice, or referenced by the media as validated information.
}

\section{Prostate Artery Embolization for Megaprostate Causing Urinary Retention, DVT and Macroscopic Haematuria Post Thrombolysis and Catheterisation: A Case Report}

\section{Ross Copping}

Liverpool Hospital

Anthony-Joe Nassour ( $\square$ anthonyjnas@gmail.com )

Liverpool Hospital https://orcid.org/0000-0002-0365-6123

Sankara Varun Bhoopathy

Liverpool Hospital

Michael Myint

Liverpool Hospital

\section{Pascal Mancuso}

Liverpool Hospital

Jules Catt

Liverpool Hospital

\section{Glen Schlaphoff}

Liverpool Hospital

\section{Research Article}

Keywords: Giant Prostatic Hyperplasia, Benign Prostatic Hyperplasia, Prostate, Embolisation, Prostate Artery Embolisation, Pulmonary Embolus, Catheter-directed thrombolysis, Deep Vein Thrombosis, Urology, Interventional Radiology, Megaprostate.

Posted Date: December 1st, 2021

DOI: https://doi.org/10.21203/rs.3.rs-1090678/v1

License: (c) (1) This work is licensed under a Creative Commons Attribution 4.0 International License. Read Full License 


\section{Abstract}

Background:

Benign prostatic hyperplasia is the most common urological condition affecting quality of life in men. Its incidence increases proportionally with age and typically manifests with mixed lower urinary tract symptoms. Giant prostatic hyperplasia, the most extreme form of BPH, can present with more serious clinical consequences and presents a challenge to surgical management.

Case presentation:

We present the first reported case of provoked deep vein thrombosis and near fatal pulmonary embolus from a symptomatic megaprostate exerting pelvic mass effect on the external iliac vein, further complicated by haematuria post catheter-directed thrombolysis.

Conclusion:

This case highlights the success of prostate artery embolization and catheter-directed thrombolysis to treat potential sequelae of giant prostate hyperplasia.

\section{Background}

Benign prostatic hyperplasia (BPH) is the most common urological condition affecting quality of life in men [1] The incidence increases with age, affecting $30 \%$ of men at age $50,60 \%$ at age 60 and $80 \%$ at age 80 [2]. BPH progresses insidiously, usually manifesting with lower urinary tract symptoms (LUTS) [3, 4]. Normal prostate volume is less than $25-30 \mathrm{cc}$ although it is well recognised that correlation between LUTS and prostatic enlargement is poor $[4,5]$. Treatment options depend on patient, disease and institutional factors.

Traditional standard of care for moderate to large BPH (40-100cc) refractory to pharmacotherapy has been endoscopic transurethral resection of prostate (TURP). Open simple prostatectomy and novel endoscopic holmium laser enucleation (HoLEP) is the recommendation for glands $>100 \mathrm{cc}$ [4]. Simple open prostatectomy is associated with significant morbidity in this setting, including peri-operative blood loss requiring transfusion (8-15\%), urinary incontinence (10\%) and urinary bladder neck stenosis or urethral strictures $(5 \%)[6,7]$.

Giant prostatic hyperplasia (GPH), also known as megaprostate, has been defined as BPH prostatomegaly with gland volume greater than 200cc [7]. Previously, GPH was defined as gland weight over $500 \mathrm{~g}$ post resection [8]. Megaprostates are uncommon, representing $4 \%$ of all BPH and typically present in the 7th decade [7, 9]. In addition to LUTS, GPH can present with macroscopic haematuria and exert mass effect on adjacent pelvic structures. Given the surgical challenges with GPH, multidisciplinary discussion is essential and consideration of prostate artery embolization (PAE) as a primary or adjunct treatment. 
We present the first reported case of provoked deep vein thrombosis (DVT) and near fatal pulmonary embolus (PE) from a symptomatic megaprostate exerting pelvic mass effect on the external iliac vein (EIV) and highlight the perfect situation supporting the use of minimally invasive PAE for successful treatment of symptomatic GPH.

\section{Case Presentation}

An 84-year-old fit and well male farmer, presented to the emergency department in distress with acute urinary retention. A three-way indwelling catheter (IDC) was inserted with relative ease, draining $500 \mathrm{~mL}$ dark rosea urine and approximately $15 \mathrm{~mL}$ clots on aspiration. He was admitted for continuous bladder irrigation (CBI). His vital signs were within normal limits. Blood tests were unremarkable with preserved renal function, haemoglobin, and coagulation profile. Digital rectal examination revealed a grossly enlarged symmetrical prostate with no focal nodularity. His prostate specific antigen (PSA) was elevated at $25.6 \mathrm{ng} / \mathrm{mL}$ but PSA density was normal at $0.038 \mathrm{ng} / \mathrm{mL}^{2}$. Initial CT demonstrated gross prostatomegaly, measuring $117 \mathrm{~mm} \times 92 \mathrm{~mm} \times 127 \mathrm{~mm}$, extending superiorly beyond the true pelvis (Fig. 1). There was no associated hydroureteronephrosis. Gland volume was calculated at $665 \mathrm{cc}$.

48-hours into his admission, he experienced a syncopal episode. Although normotensive, he was found to be in rapid atrial fibrillation (heart rate $140 \mathrm{bpm}$ ) with a troponin leak of $300 \mathrm{ng} / \mathrm{mL}$, tachypneic (respiratory rate 24 ) and hypoxic (oxygen saturation $91 \%$ on $10 \mathrm{~L}$ oxygen).

CT Pulmonary-Angiogram (CTPA) revealed extensive bilateral, non-occlusive PE extending distally from the main pulmonary arteries associated with features of right ventricular strain on CT and echocardiogram. He was commenced on a heparin infusion, transferred to our tertiary centre and referred to interventional radiology. Not unexpectedly, the anticoagulation exacerbated the haematuria and CBI was recommenced.

72-hours into his admission, he underwent catheter-directed thrombolysis. Two $90 \mathrm{~cm}$ fountain catheters (10 cm infusion lengths) (Merit Medical, Utah, USA) were positioned in the left and right pulmonary arteries via right femoral vein access. Alteplase was infused at $1 \mathrm{mg} / \mathrm{hour}$ via each infusion catheter (total $2 \mathrm{mg} /$ hour) for 24-hours. Remarkably, check pulmonary angiogram 24-hours post thrombolysis showed complete resolution of the bilateral PE down to the segmental level. Significant extrinsic compression of the right iliac veins was noted between the megaprostate and the external and internal iliac arteries, limiting flow and causing some resistance to catheters and wires traversing the stenosis (Figure 2). Lower limb dopplers confirmed right below knee DVT, but it was suspected that the largest component of the DVT had already embolised to the pulmonary circulation.

Following multidisciplinary and patient discussion, there was consensus that PAE would be the best treatment choice to manage the ongoing intractable haematuria in the context of therapeutic anticoagulation and shrink the megaprostate to alleviate iliac venous compression and urinary symptoms in the longer term. Transarterial particle embolisation of the prostate was performed via left 
conventional radial access (Figure 3). A $150 \mathrm{~cm}$ 4Fr NaviCross catheter and glidewire (Terumo, Japan) were navigated down to the pelvis before subselection with a $167 \mathrm{~cm}$ headway duo microcatheter (Microvention Terumo, California, USA) and an .014" synchro soft wire (Stryker, California, USA). Angiography showed a single dominant prostate artery on each side. The left prostate artery was a branch of a replaced left obturator artery arising off the left external iliac artery. The right prostate artery was a branch of the right obturator artery, arising conventionally off the anterior division of the right internal iliac artery. 100-300um Embospheres (Merit Medical, Utah, USA) were used, with $116 \%$ of a vial injection on the left and $48 \%$ on the right until stasis, using the PErFecTED technique [10]. There was complete resolution of macrohaematuria within 24-hours of embolization and successful trial-of-void performed at first attempt 14-days post procedure. His clinical scores also conveyed significant functional improvement. Prior to the PAE, his IPSS was 15, QOL 5 and SHIM 17. One month post PAE, he reported IPSS 2 (residual nocturia), QOL 0 and a post-void residual volume of $8 \mathrm{~mL}$ on renal tract ultrasound. There is a plan for progress MR at 6 months and consideration of repeat PAE if there are residual or recurrent symptoms at that time.

\section{Conclusions}

Giant Prostatic Hyperplasia (GPH) is a rare pathology that can present with LUTS, haematuria or atypically with sequalae from pelvic mass effect. GPH can cause DVT/PE due to pelvic mass affect and CTD is an effective treatment option in this setting. Although simple open prostatectomy remains firstline treatment in many centres for symptomatic GPH, PAE is minimally invasive and often a safer alternative for immediate and long-term symptomatic control in suboptimal surgical candidates.

\section{Abbreviations}

BPH: Benign Prostatic Hyperplasia

LUTS: Lower Urinary Tract Symptoms

TURP: Transurethral Resection of the Prostate

HoLEP: Holmium Laser Enucleation of the Prostate

GPH: Giant Prostatic Hyperplasia

DVT: Deep Vein Thrombosis

PE: Pulmonary Embolus

PAE: Prostate Artery Embolisation

IDC: Indwelling Catheter 
CBI: Continuous Bladder Irrigation

CTKUB: Computed Tomography Kidney-Ureter-Bladder

rAF: Rapid Atrial Fibrillation

CVF: Common Femoral Vein

EIV: External Iliac Vein

IPSS: international prostate symptom score

SHIM: sexual health inventory for men

QOL: quality of life

\section{Declarations}

\section{Ethical Approval and Consent to Participate}

- Ethical approval not required for case report. Written consent to participate was obtained by patient.

\section{Consent for Publication}

- Written informed consent was obtained from the patient for publication of this case report and any accompanying images

\section{Availability of Data and Materials}

- All data and materials are securely stored within the patient's electronic medical records

\section{Competing Interests}

- None to disclose

\section{Funding}

- None to disclose

\section{Authors' Contributions}

- All authors significantly contributed to the final submission of this manuscript

- Copping R - First draft (case presentation and image selection) 
- Nassour AJ - First draft (abstract, background and conclusion)

- Bhoopathy $\mathrm{V}$ - Edit and formatting

- Myint M - End and formatting

- Mancuso P - Edit and review of background

- Catt $\mathrm{J}$ - Edit and review of background

- Schlaphoff G - Edit, image editing, embilization technique

\section{Acknowledgements}

- Not applicable

\section{Authors' Information}

- Dr Anthony-Joe Nassour.

- E: anthonyjnas@gmail.com.

○ $\mathrm{T}:+61405959444$

- A: 3707/343 Pitt Street Sydney NSW, 2000, Australia

\section{References}

1. Donovan JL, Kay HE, Peters TJ et al (1997) Using the ICSOoL to measure the impact of lower urinary tract symptoms on quality of life: evidence from the ICS-'BPH' Study. International Continence Society-Benign Prostatic Hyperplasia. Br J Urol 80:712-721

2. Wang W, Guo Y, Zhang D et al (2015) The prevalence of benign prostatic hyperplasia in mainland China: evidence from epidemiological surveys. Sci Rep 5:13546

3. Welliver C, Sulaver R, Whittington A et al (2015) Analyzing Why Men Seek Treatment for Lower Urinary Tract Symptoms and Factors Associated With Nonimprovement. Urology 86:862-867

4. Foster HE, Barry MJ, Dahm P et al (2018) Surgical Management of Lower Urinary Tract Symptoms Attributed to Benign Prostatic Hyperplasia: AUA Guideline. J Urol 200:612-619

5. Mitterberger M, Horninger W, Aigner F et al (2010) Ultrasound of the prostate. Cancer Imaging 10:4048

6. Oelke M, Bachmann A, Descazeaud A et al (2013) EAU Guidelines on the Treatment and Follow-up of Non-neurogenic Male Lower Urinary Tract Symptoms Including Benign Prostatic Obstruction. Eur Urol 64:118-140

7. Somwaru AS, Metting S, Flisnik LM et al (2020) Prostate artery embolization has long term efficacy for treatment of severe lower urinary tract symptoms from giant prostatic hyperplasia. BMC Urol 20:153

8. Fishman JR, Merrill DC (1993) A case of giant prostatic hyperplasia. Urology 42:336-337 
9. Berry SJ, Coffey DS, Walsh PC et al (1984) The Development of Human Benign Prostatic Hyperplasia with Age. J Urol 132:474-479

10. Carnevale FC, Moreira AM, Antunes AA (2014) The "PErFecTED technique": proximal embolization first, then embolize distal for benign prostatic hyperplasia. Cardiovasc Intervent Radiol 37:16021605

\section{Figures}

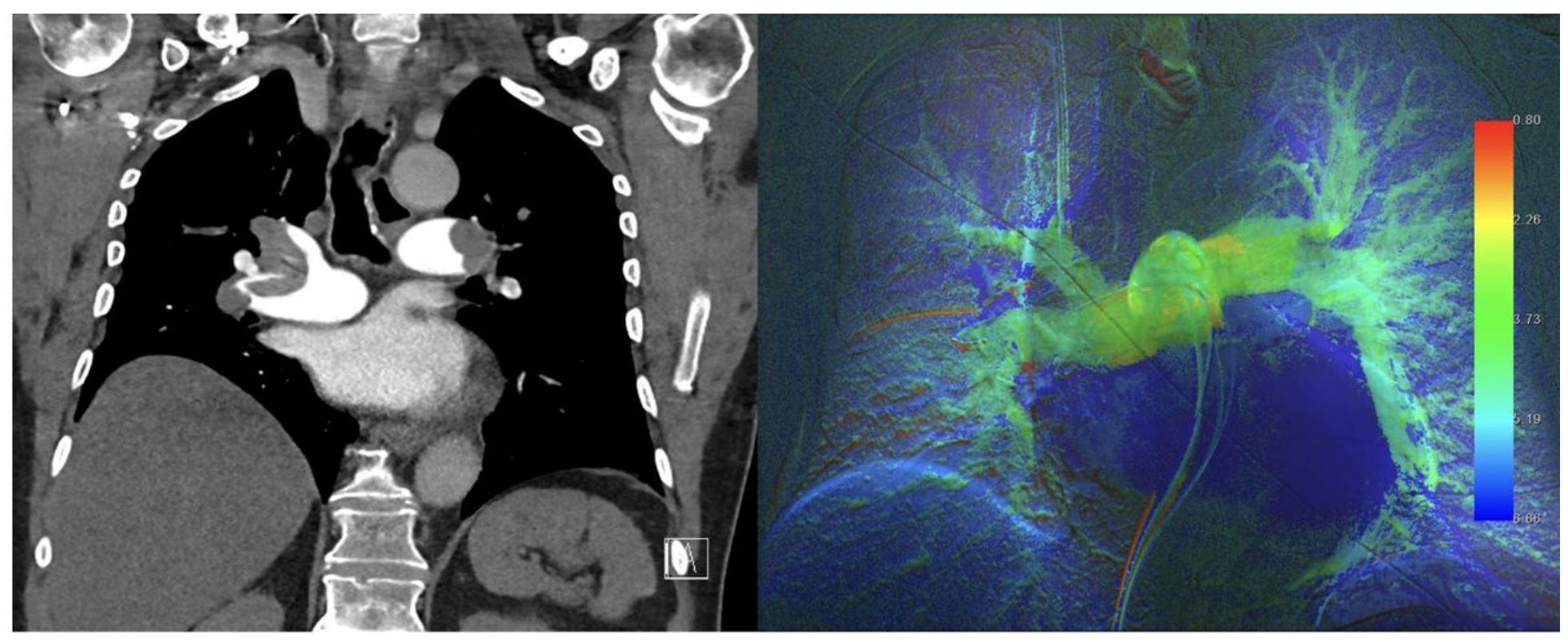

\section{Figure 1}

(a) CT pulmonary angiogram in the coronal plane showing bilateral central pulmonary emboli, extending distally from the main pulmonary arteries (b) 2D perfusional angiography reconstructed from the final check pulmonary angiogram showing complete resolution of the PE post catheter-directed thrombolysis. 


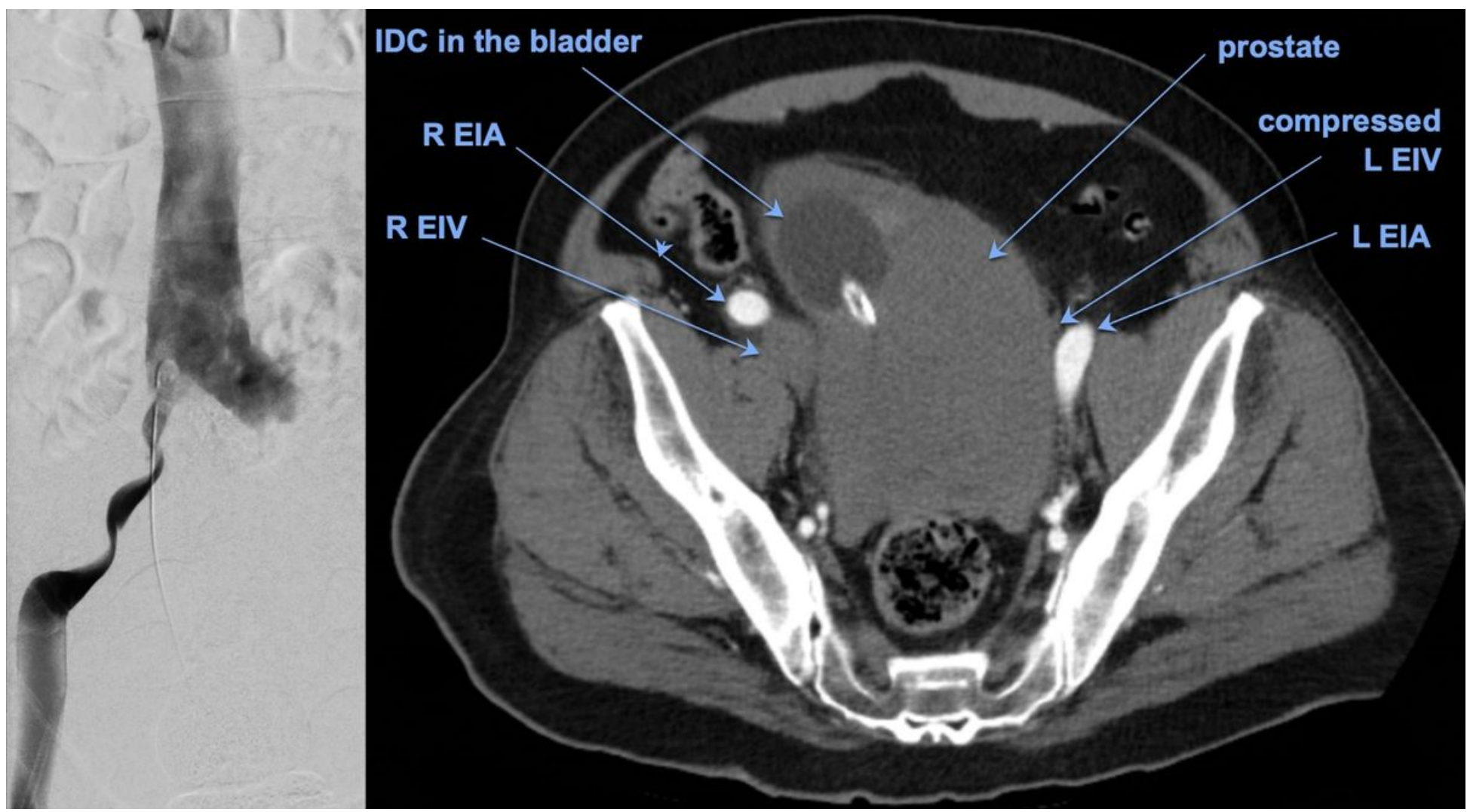

Figure 2

(a) venogram via the right femoral sheath showing extrinsic compression and narrowing of the left iliac veins. The inferior impression is from the external iliac artery and the superior impression is from the internal iliac artery (b) CT angiogram of the pelvis in the axial plane with bilateral labelled structures for comparison. The left iliac vein is compressed by the iliac arteries and pelvis sidewall, as seen on the venogram. 


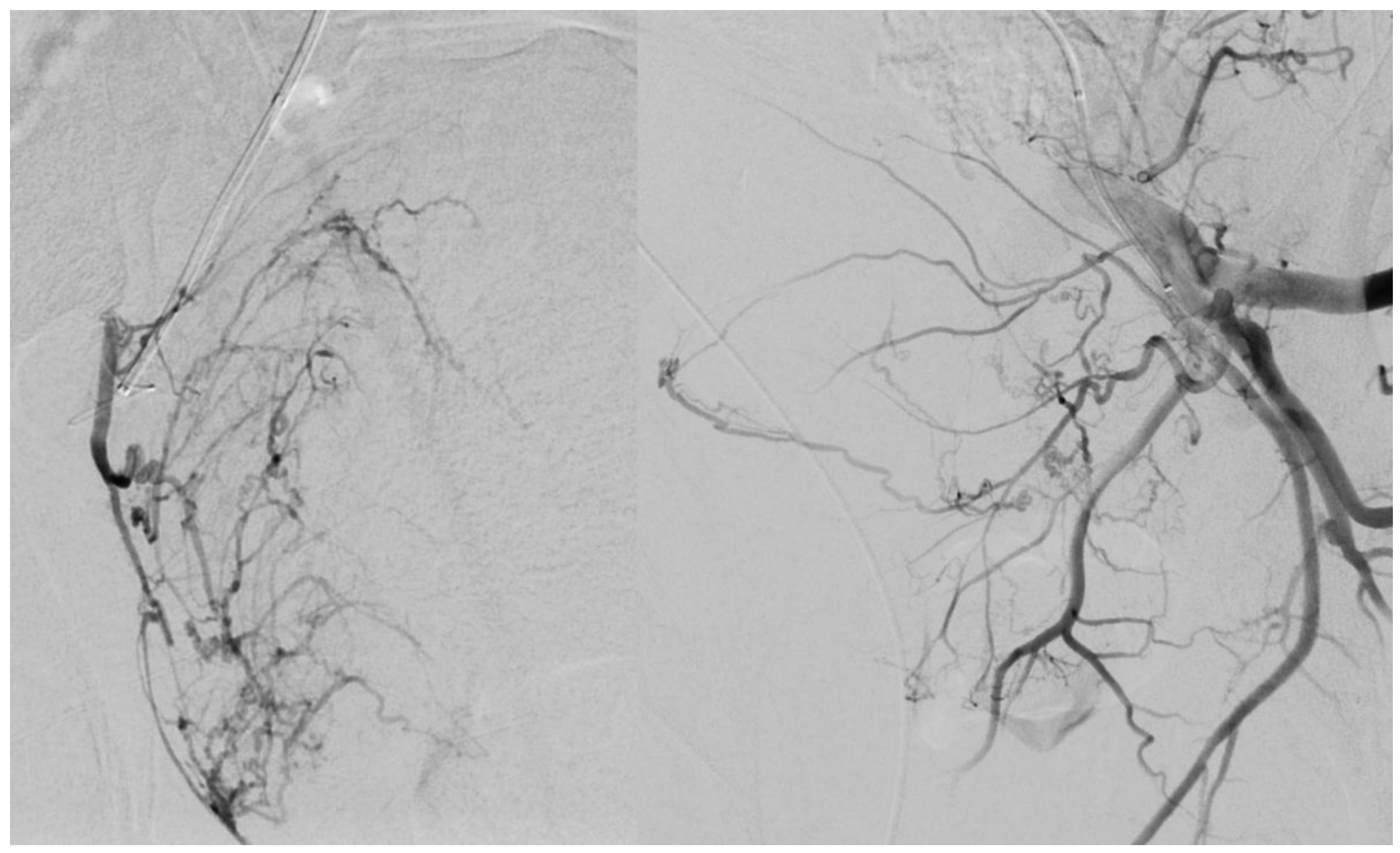

\section{Figure 3}

(a) angiogram via the microcatheter in the right prostate artery. The base catheter is positioned in the right obturator artery which arises conventionally off the anterior division of the internal iliac artery (b) the left prostate artery arises from the left obturator artery, which is replaced arising from the left external iliac artery. 